\title{
What Massachusetts Residents Know about Fluoridation*
}

\author{
Jane A. Weintraub, DDS, MPH ${ }^{\dagger}$ \\ Program in Dental Public Health \\ School of Public Health \\ The University of Michigan \\ Ann Arbor, Ml 48109-2029
}

\section{Gregory N. Connolly, DMD, MPH}

Division of Dental Health

Massachusetts Department of Public Health

Boston, MA 02111

\section{Craig A. Lambert, PhD}

Formerly with the

Massachusetts Department of Public Health

\section{Chester W. Douglass, DDS, PhD}

Department of Dental Care Administration

Harvard School of Dental Medicine

Boston, MA 02115

\begin{abstract}
The Massachusetts Department of Public Health conducted a comprehensive, statewide telephone health interview survey during 1980. Adult members of 1,091 households were interviewed. The purpose of this paper is to report the attitudes and knowledge of the Massachusetts residents surveyed regarding fluoridation, as well as the relation of their attitudes with demographic and socioeconomic variables, dental and other health behaviors, and outcome of fluoridation referenda. The majority, 60 percent, were in favor of community water fluoridation. As expected, groups that were most likely to favor fluoridation were parents, those who were better educated, and those with higher incomes. About three-fourths of those surveyed were correctly aware of the purpose of fluoridation. Public opinion about fluoridation, as measured by this survey, did not correspond with the outcome of fluoridation referenda held in 14 Massachusetts communities between 1980 and 1983, which showed that 61 percent of the voters were not in favor of fluoridation.
\end{abstract}

Key Words: fluoridation, preventive dentistry, public health dentistry, community decision making

\section{Introduction}

The efficacy and cost-effectiveness of community water fluoridation as well as the attitudes toward and knowledge of this public health measure have

* Supported in part by a Health Education Risk Reduction Grant (H11/CCH100235-02) from the Centers for Disease Control, Public Health Service, USDHHS.

tPlease address correspondence and reprint requests to Dr. Weintraub. been well documented (1-6). Many surveys have been conducted to monitor the public's opinion on this issue. Indeed, on election day a fluoridation "survey" generally occurs in states were a referendum must be approved by the voters before the concentration of fluoride in a community's water supply can be adjusted to an optimum level for dental health. Massachusetts is such a state and a statute passed in 1968 requires that a referendum be placed on the ballot if 10 percent of the registered voters file a petition within 90 days of publication of a Board of Health order to fluoridate. In 1975, before the fluoridation of Boston's Metropolitan Water District, Massachusetts ranked 44th among the 50 states according to the percentage of its population using natural or adjusted fluoridation (21.6 percent (7)). In 1978, administrative action of the majority of 33 cities or towns resulted in the fluoridation of Boston's Metropolitan Water District. By 1980, about half of the residents of Massachusetts were receiving the benefits of fluoridation. Thus, it is necessary to continue to monitor the public's opinion on this issue and assess changes so that the most effective fluoridation strategies can be developed and implemented successfully.

This paper reports the attitudes of Massachusetts consumers toward fluoridation, based on the results of a statewide health interview survey.

\section{Methods}

A comprehensive health interview survey was conducted by telephone during September 1980 by specially trained interviewers from Clark University's Public Affairs Research Center for the Massachusetts Department of Public Health. The sampling design and survey research methods used to obtain a representative sample of the six Health 
TABLE 1

Demographic Characteristics of the Sample as Compared with Those Reported in the 1980 US Census

\begin{tabular}{lrcc}
\hline & & \multicolumn{2}{c}{ Percentage } \\
\cline { 4 - 4 } Characteristic & Number of Respondents & Sample & 1980 Census \\
\hline Sex & & & \\
$\quad$ Male & 470 & 43.1 & 46.6 \\
Female & 621 & 56.9 & 53.4 \\
Total & 1,091 & - & - \\
Age (years) & & & \\
16-24 & 187 & 17.1 & 22.4 \\
$25-44$ & 449 & 41.2 & 35.0 \\
$45-64$ & 278 & 25.2 & 26.3 \\
$65-90$ & 177 & 16.2 & 16.3 \\
Total & 1,091 & - & - \\
Median income & 1,091 & $\$ 17,662$ & $\$ 17,575$ \\
\hline
\end{tabular}

TABLE 2

Results of 1980 Massachusetts Survey and 1979 Gallup Organization, Inc., Survey concerning Purpose of Water Fluoridation

\begin{tabular}{lrrr}
\hline & \multicolumn{2}{c}{ Mass. } & U.S. \\
\cline { 2 - 3 } & \multicolumn{1}{c}{$\mathrm{n}$} & $\%$ & $\%$ \\
\hline Purpose of Fluoridation & 826 & 75.9 & - \\
To improve dental health & - & - & 49 \\
To reduce tooth decay & 88 & 8.1 & 23 \\
To purify water & 4 & 0.4 & 6 \\
To reduce pollution & 4 & 0.4 & 4 \\
To improve the taste & 36 & 3.3 & - \\
Other & 129 & 11.9 & 18 \\
Do not know/No answer & 1089 & 100.0 & 100.0 \\
Total &
\end{tabular}

Service Areas in the state have been reported $(8,9)$. If necessary, four attempts were made to reach each selected household, and 1,797 households were contacted. Of this group, adult members of 1,091 households (61.1 percent) agreed to be interviewed. A 121-item schedule of questions was administered, which required a median time of 16 minutes to complete. Adults were interviewed regarding their use of medical and dental services, personal health habits, exposure to occupational and environmental hazards, and attitudes toward public health issues, including fluoridation.

\section{Results}

\section{The Sample}

The sample included adults ranging in age from 16 to 90 with a median age of 38.9 years. This distribution compared favorably with the median age of 39.9 years reported by the 1980 United States Census for the national population. The sample approximated the state's adult population in terms of age, sex, and median household income (see Table 1) (9). The median educational level of the sample was 11.9 years, slightly higher than the median of 11.6 years reported by the 1980 United States Cen- sus for Massachusetts (10). Detailed demographic characteristics of the sample population have been reported by Lambert et al. (8).

When evaluating the findings, one must keep in mind that all results were based on self-reported data, which were necessary to obtain attitudinal information, but which may not be as reliable as objective data.

\section{Knowledge about Fluoridation}

The first question regarding fluoridation asked of the respondents was: "To the best of your knowledge, what is the purpose of adding fluoride to the drinking water?" The responses to this open-ended question are presented in Table 2. The correct answer, to improve dental health, was given by 76 percent of the respondents. Incorrect answers, such as to purify water, improve taste, reduce pollution, and others were given by 12 percent of the respondents. The remaining 12 percent either did not know or did not answer the question.

In 1977, a similar question was asked in personal interviews of a national sample of 1,517 adults by the Gallup Organization for the US General Accounting Office (11). The question was phrased: "As you understand it, which one of the items on 
this card best describes the purpose of public water fluoridation?" The choice of items and the responses given are presented in Table 1. Only about half of the national sample, as compared to three-fourths of the Massachusetts sample, gave the correct response.

When the answers to the first question about fluoridation on the Massachusetts survey were analyzed according to different demographic characteristics, a strong, positive relation was found between correct knowledge of the purpose of fluoridation and increasing levels of education and income. This finding was also observed in the national study. Adults in the 25- to-44-year-age range were most likely to answer this question correctly, and 83 percent did so. Only 60 percent of the adults in the oldest age category, 65 to 90 years, gave the correct response. This finding highlights the need to educate senior citizens about the purpose of fluoridation, especially because they are an important voting block. One might expect that parents who are watching the growth and development of their child's dentition are also likely to be more concerned about factors that affect their child's dental health. Accordingly, it was found that adults who had children residing in their households were more likely to know the purpose of fluoridation than those in households without children. Both the Massachusetts and Gallup surveys show no significant difference between men and women regarding their knowledge of the purpose of fluoridation.

Correct knowledge of fluoridation also seems to be associated with other dental attitudes and behaviors. For example, 80 percent of persons most concerned about decayed teeth and 80 percent of persons most concerned about missing teeth correctly answered this question, as compared to 64 percent who were most concerned about dentures. Of those who had visited a dentist within the past year, 79 percent knew the purpose of fluoridation, as compared to 69 percent of those whose last dental visit was more than a year ago. This finding may indicate that the dental office is a source of information where people are learning about fluoridation. However, some types of visits may be more conducive to such a discussion than others. Seventy-nine percent whose last dental visit was for a checkup and cleaning and 77 percent whose last visit was for a restoration gave the correct response, but only 71 percent of patients whose last visit had been for an extraction or of an emergency nature knew the correct purpose of fluoridation.

\section{Fluoridation Status of Community Water Supply}

Consumers were also asked: "Does your water supply have fluoride added to it?" Close to 40 percent of the respondents said that fluoride was added to their water supply. At the time this survey was conducted, approximately 50 percent of the public water supplies in Massachusetts had been fluoridated. Surprisingly, the educational level obtained by the respondents had little effect on their ability to answer the question about their drinking water. In fact, 33 percent of persons with postgraduate training did not know if their water was fluoridated, as compared to only 23 percent of persons who were high school graduates. One hypothesis is that the group with the highest educational level is also the most mobile. Newcomers in a community may be less likely to have obtained fluoridation information about their drinking water. Frequently, education and income levels exhibit parallel relations with other factors. Relative to this question, however, the trends were in opposite directions. The percentages of respondents who did not know if their water was fluoridated decreased with increasing income level from 33 percent of persons earning less than $\$ 10,000$ to 20 percent of those earning more than $\$ 20,000$ a year. The findings of the survey also suggest that the respondents' age was not a significant factor in determining whether or not they knew if their water supply was fluoridated.

\section{"Although there are no significant differences among attitudinal groups with respect to the purpose of their last dental visit, respondents who reported that their last visit was for an emergen- cy or extraction were least likely to fa- vor fluoridation and most likely to have no opinion."}

Since many areas of the Commonwealth, particularly the Boston metropolitan area, have been fluoridated for only a relatively short time, it is too soon for fluoridation to have its full effect on the utilization of dental services in Massachusetts. In addition, it must be remembered that persons residing in nonfluoridated areas are also receiving fluoride in other forms, such as fluoride-containing dentifrices, fluoride supplements and mouthrinses, topical treatments applied by a dental professional, and in food that is part of their regular diet. A clear-cut distinction can no longer be made between those who do and do not receive fluoride based solely on the concentration in their drinking water.

The responses to the question, "Does your water supply have fluoride added to it?" according to Health Service Area (HSA), are presented in Table 3 . These responses represent the consumers' perceived knowledge of the fluoridation status of their drinking water. The percentage of the population actually receiving fluoridated water in each HSA according to the 1978 state fluoridation census is also presented (12). 
TABLE 3

Percentage Distribution of Responses to Question, "Does Your Water Supply Have Fluoride Added to it?" by HSA

\begin{tabular}{lccccccc}
\hline & \multicolumn{7}{c}{ Health Service Area } \\
\cline { 2 - 7 } Response & 1 & 2 & 3 & 4 & 5 & 6 & Total \\
\hline Yes & 32.2 & 31.4 & 37.2 & 44.9 & 31.6 & 53.0 & 39.5 \\
No & 47.5 & $\mathbf{4 7 . 3}$ & 40.1 & 23.2 & 47.1 & 18.2 & 34.4 \\
Do not know & 20.3 & 21.3 & 22.7 & 31.9 & 21.4 & 28.7 & 26.1 \\
Actual & 7.0 & 17.6 & 25.3 & 82.2 & 33.2 & 81.7 & 51.2 \\
\hline
\end{tabular}

TABLE 4

Percentage Distribution of Attitude toward Fluoridation and Actual Fluoridation Status by HSA

\begin{tabular}{cccccc}
\hline & \multicolumn{3}{c}{ Attitude } & & Actual Status \\
\cline { 2 - 4 } HSA & Favor & Oppose & No Opinion & \% Fluoridated \\
\hline 1 & 61.4 & 28.7 & 9.9 & 7.0 \\
2 & 58.8 & 24.7 & 16.5 & 17.6 \\
3 & 68.5 & 15.8 & 15.8 & 25.3 \\
4 & 63.8 & 23.0 & 13.2 & 82.2 \\
5 & 55.5 & 25.3 & 19.2 & 33.2 \\
6 & 72.9 & 13.3 & 13.9 & 81.7 \\
\hline
\end{tabular}

Consumers residing in HSA 6, the North Shore Area, were most likely to report living in a fluoridated area. This answer was to be expected because many of the communities in this area, such as Salem, Danvers, and Beverly, were among the first in the state to adjust their fluoride levels and have been fluoridated since the 1950s. It is apparent, however, that many people were making one of two types of errors - either thinking that their water is not fluoridated, when in fact it is, as in HSAs 4 and 6, or that it is fluoridated when it is not, as was apparent in HSAs 1, 2, and 3.

\section{Attitudes toward Fluoridation}

Participants were asked: "Do you favor or oppose adding fluorides to municipal drinking water?" The majority, 60 percent of all of the consumers interviewed, "strongly favor" or "favor" adding fluoride to municipal drinking water. Almost three times as many people were in favor of fluoridation as were opposed to it. A greater proportion of Massachusetts consumers were in favor of fluoridation than was found in the 1977 national Gallup survey. Results of the national survey showed that 51 percent of the respondents felt that public water fluoridation was "very desirable" or "desirable."

Table 4 presents the attitudes of Massachusetts residents toward fluoridation according to geographic region and current fluoridation status (12). According to the health interview survey, the percentage of people in favor of fluoridation in each health service area was at least twice as great, and in one area, more than five times as great, as the percentage of people opposed to fluoridation. In health service areas 1,2,3, and 5, the percentage of people receiving fluoridated water dramatically lags behind the percentage of people who are in favor of fluoridation. There is only a moderate correlation between consumers' attitudes toward fluoridation and their actual fluoridation status $(\mathrm{r}=.52)$.

The percentage distribution of the three attitudinal groups with respect to education, income, and parental status are presented in Tables 5 and 6 . Chisquare tests conducted on the frequency data reveal significant differences with respect to education $(\mathrm{p}=.049)$, income $(\mathrm{p}=.003)$, and parental status $(p=.002)$; but not with respect to age $(p=.098)$ and $\operatorname{sex}(p=.195)$, when these latter two variables are analyzed. As expected from other studies $(13,14)$, as education and income levels increase, those in favor of fluoridation also increase. Simultaneously, those with no opinion decrease.

Respondents in the 25-to-44-year-old age group were most likely to favor fluoridation and least likely to have no opinion. The opposite was true for the oldest age group. A greater percentage of the women than the men interviewed were in favor of fluoridation; however, this difference- 65 percent compared to 59.8 percent-was not statistically significant. In terms of parental status, Table 6 shows that active mothers, defined as mothers with children living with them, were the most likely group to support fluoridation and men without children were the least likely group to support fluoridation.

Of additional interest is the relation between residents' dental health behaviors and fluoridation attitudes. Respondents who had visited a dentist within the past year were somewhat more likely to be in favor of fluoridation (66 percent) than those whose last dental visit was more than a year ago (57 percent). With a chi-square test on the frequency data, 
TABLE 5

Percentage Distribution of Attitude toward Fluoridation by Education and by Income

\begin{tabular}{|c|c|c|c|c|c|c|c|}
\hline \multirow[b]{2}{*}{ Attitude } & \multicolumn{4}{|c|}{ Education } & \multicolumn{3}{|c|}{ Income } \\
\hline & $\begin{array}{l}\text { 0-11th } \\
\text { Grade }\end{array}$ & $\begin{array}{c}\text { High } \\
\text { School }\end{array}$ & $\begin{array}{c}\text { Any } \\
\text { College } \\
\end{array}$ & Postgraduate & $<\$ 10,000$ & $\begin{array}{l}\$ 10,000 \\
\$ 20,000\end{array}$ & $>\$ 20,000$ \\
\hline Favor & 55.8 & 61.1 & 64.3 & 74.4 & 58.4 & 61.0 & 70.5 \\
\hline Oppose & 26.2 & 24.6 & 22.2 & 13.6 & 22.4 & 24.1 & 20.1 \\
\hline No Opinion & 18.0 & 14.3 & 13.5 & 12.1 & 19.2 & 14.9 & 9.4 \\
\hline
\end{tabular}

Education: $p=.049$; Income: $p=.003$.

TABLE 6

Percentage Distribution of Attitude toward Fluoridation by Parental Status

\begin{tabular}{lcccc}
\hline & \multicolumn{4}{c}{ Parental Status } \\
\cline { 2 - 5 } Attitude & $\begin{array}{c}\text { Active } \\
\text { Father }\end{array}$ & $\begin{array}{c}\text { Male w/o } \\
\text { Child }\end{array}$ & $\begin{array}{c}\text { Active } \\
\text { Mother }\end{array}$ & $\begin{array}{c}\text { Female w/o } \\
\text { Child }\end{array}$ \\
\hline Favor & 62.3 & 57.8 & 72.4 & 59.5 \\
Oppose & 26.3 & 22.2 & 18.1 & 24.6 \\
No opinion & 11.5 & 20.0 & 9.5 & 15.9 \\
\hline
\end{tabular}

$\mathrm{p}=.002$.

significant differences were found among the three attitudinal groups with respect to the dental problem that they reported as being of greatest concern to them $(p=.001)$. The groups who are most concerned with "decayed teeth" or "crooked teeth" are the groups most likely to be in favor of fluoridation. Although there are no significant differences among attitudinal groups with respect to the purpose of their last dental visit, respondents who reported that their last visit was for an emergency or extraction were least likely to favor fluoridation and most likely to have no opinion.

When consumers' responses to the question regarding the purpose of fluoridation were compared to their attitudes toward fluoridation, it was apparent that persons who have correct knowledge of the purpose of fluoridation were more likely to favor this procedure (69 percent). Similarly, persons who did not know the purpose of fluoridation were more likely to have no opinion or to oppose the measure. These findings highlight the important favorable relation between consumer knowledge and attitudes toward fluoridation.

\section{Other Health Behaviors}

It was expected that respondents who favored fluoridation would exhibit other positive health behaviors. To test this assumption, attitudes toward fluoridation were related to use of salt and vitamins. There was no significant difference found among the proportions of the three attitudinal groups with respect to their use of salt in their diet or whether or not they take a vitamin or mineral supplement every day. Although persons in support of fluoridation were more likely to have seen a dentist within the past year, they were not more likely than persons opposed to fluoridation to have seen a physician within the past year. Thus, it is difficult to relate respondents' attitudes toward fluoridation to other health behaviors.

\section{Discussion}

What about the relation between fluoridation attitudes, as determined by a public opinion survey, and voter behavior during a fluoridation referendum? In 1968, Sapolsky (15) found that opinion surveys conducted before a referendum usually favor fluoridation by a large majority, but when a vote is held the measure has a 60 percent chance of being defeated. In a recent review of social research regarding fluoridation, Frazier (16), came to a similar conclusion.

Since 1980, 16 referenda had been held in 14 cities and towns in Massachusetts. Two communities each had two referenda; one was advisory and in the second one the outcome was binding. Of the 14 final outcomes, the fluoridation measure was passed in three communities and defeated in 11. Of the people who actually voted in these 14 referenda, 43,208 (39 percent) voted in favor and 66,760 (61 percent) voted against it. The 109,968 voters represented 45.6 percent of the 241,369 voters registered, based on 1980 election statistics, and 23.3 percent of the total population of 472,394 of the 14 communities, according to 1980 census tract data. Thus attitudes toward fluoridation as measured by this survey, which indicated 60 percent of persons surveyed were in favor of fluoridation, did not correspond with the outcome of the referenda, which showed that 61 percent of the voters were not in favor of fluoridation.

There are many possible explanations for this disagreement. First, the sampling frame used to select a random sample of the population is not the same as the sampling frame of all registered voters. People who vote in an election do not constitute a random sample of the population. In addition, as Faine (17) points out, the antifluoridationists are good at obtaining a large turn-out of voters for their cause. Another partial explanation is that voters often change their minds during a fluoridation campaign. 


\section{"Thus, attitudes toward fluoridation as measured by this survey, which indicated 60 percent of persons surveyed were in favor of fluoridation, did not correspond with the outcome of the referenda, which showed 61 percent of the voters were not not in favor of fluoridation."}

Sapolsky (18) developed what has later been described by Hastreiter (19) as the confusion hypothesis. During a fluoridation campaign, voters are presented with scientific-sounding arguments by both pro- and antifluoridationists. Both groups are often represented by professionals. The public, therefore, has difficulty judging who in fact is a fluoridation expert and which arguments are valid and should be trusted. As a result, the voters can postpone adoption until they judge that the conflict has been resolved.

On the more positive side, since 1980, five communities in Massachusetts, with a combined population of 275,000 , initiated fluoridation under a Board of Health order that was not challenged by petition and did not go to the public referenda. A critical factor in having these communities fluoridate was availability of funding for fluoridation from the federal categorical fluoridation grant program administered by the federal Centers for Disease Control and from the Preventive Health and Health Services Block Grant. Without these funds, it is questionable whether or not the communities would have instituted fluoridation. It was also fortunate that a referendum did not occur in these communities and that the Board of Health order was not challenged. In 1980, fluoridation campaigns were unsuccessful in 23 out of 24 small towns with populations of less than 10,000 (20). Fluoridation is more likely to be implemented by a vote of the city council than in a general election. In 1984, the American Association of Public Health Dentistry Subcommittee on Community and School Water Fluoridation (21) recommended that, where possible, efforts should be made to have fluoridation introduced through community leaders and the local governing body without a referendum. In small towns, it is especially critical for the mayor to have a favorable opinion of fluoridation and for many proponents to be present and express their views at the city council meeting if fluoridation is to be adopted (22). Proponents must also be prepared to wage a campaign against well-organized, vocal opposition.

Public referenda on adoption of a proven public health measure may result in its rejection and the denial of health benefits to a sizable portion of the population even though popular support exists for it. No other public health measure is subject to routine voter approval. It would appear that fluoridation would more likely be initiated if state legislatures amended their fluoridation statutes to treat fluoridation in a manner similar to other public health measures.

\section{Conclusions}

As part of a statewide health interview survey, 1,091 individuals were questioned about their knowledge and attitudes toward fluoridation. The majority of the consumers throughout the Commonwealth of Massachusetts who were interviewed for this survey were in favor of community water fluoridation (60 percent). An even greater percentage, 76 percent, were correctly aware of the purpose of fluoridation. People most likely to favor fluoridation were those with higher rather than lower levels of education and income, correct knowledge of the purpose of fluoridation, concern about "decayed" or "crooked" teeth, between the ages of 25 and 44 , and mothers with children living with them. Public opinion about fluoridation, as measured by this survey, did not correspond with the outcome of fluoridation referenda held in 14 Massachusetts communities between 1980 and 1983.

\section{References}

1. Arnold FA Jr., Likins RC, Russell AL, Scott DB. Fifteenth year of Grand Rapids fluoridation study. J Am Dent Assoc 1962;65:780-5.

2. AST DB, Cons NC, Pollard ST, Garfinkel J. Time and cost factors to provide regular periodic dental care for chilren in a fluoridated and nonfluoridated area: final report. J Am Dent Assoc 1970 April;80:770-6.

3. Barrett $S$, Rovin $S$, eds. The tooth robbers: a pro-fluoridation handbook. Philadelphia: George F. Stickley Company, 1980.

4. Burt BA, ed. The relative efficiency of methods of caries prevention in dental public health: proceedings of a conference at the University of Michigan, June 6-8, 1978. Ann Arbor: University of Michigan, 1979.

5. Dunning JM. Current status of fluoridation. $N$ Engl J Med 1965;272:30-3,84-8.

6. Striffler DF, Young WO, Burt BA. Dentistry, dental practice, and the community. Philadelphia: WB Saunders, 1983.

7. US Department of Health, Education, and Welfare. Public Health Service, Centers for Disease Control. Fluoridation census 1975. Atlanta: US Government Printing Office, April 1977, p.7.

8. Lambert CA, Netherton DR, Finison LJ, Hyde JN, Spaight SJ. Risk factors and life style: a statewide health interview survey. N Engl J Med 1982;306:1048-51.

9. Weintraub JA, Connolly GN, Douglass CW, Lambert CA. Attitudes toward dental health and utilization of dental services by Massachusetts consumers. J Mass Dent Soc 1983 Spring;32:20-8.

10. US Bureau of the Consensus. Summary 212-3A Print-Out for Massachusetts. Boston, MA, 1980.

11. Comptroller General, Report to the Congress of the United States. Reducing tooth decay-more emphasis on fluoridation needed. Washington, DC: US General Accounting Office, April 13, 1979. HRD-79-3, p.41.

12. Massachusetts Department of Public Health, Office of State Health Planning and Statewide Health Coordinating Council. 1979 State Health Plan, Primary Dental Care and Dental Health Component. Boston, MA. p.28. 
13. Simmel A, Ast DB. Some correlates of opinion on fluoridation. Am J Public Health 1962;52:1269-73.

14. Metz AS. An analysis of some determinants of attitude toward fluoridation. Social Forces 1966;44:477-84.

15. Sapolsky HM. Science, voters, and the fluoridation controversy. Science 1968 Oct;162:427-33.

16. Frazier PJ. Fluoridation: a review of social research. J Public Health Dent 1980 Summer;40:214-33.

17. Faine RC. An agenda for the eighties: community and school fluoridation. J Public Health Dent 1980 Summer;40:258-67.

18. Sapolsky HM. The fluoridation controversy: an alternative explanation. Public Opinion Q 1969 Summer;33:240-8
19. Hastreiter RJ. Fluoridation conflict: a history and conceptual synthesis. J Am Dent Assoc 1983 April;106:486-90.

20. Faine RC, Collins JJ, Daniel J, et al. The 1980 fluoridation campaigns: a discussion of results. J Public Health Dent 1981 Summer;41:138-42.

21. American Association of Public Health Dentistry Subcommittee on Community and School Water Fluoridation. Community and school water fluoridation; summary and recommendations. ] Public Health Dent 1984 Winter;44:43-6.

22. Hunt RJ. Community characteristics, opinion leadershiip and fluoridation outcome in small lowa communities. I Public Health Dent 1983 Spring;43:152-60. 